\title{
Domiciliary exhaled nitric oxide and eosinophilic airway inflammation in adults with asthma
}

\section{To the Editor:}

Sputum eosinophils are the gold standard measure of eosinophilic airway inflammation and there is strong evidence that titrating corticosteroid therapy to sputum eosinophils reduces the rate of asthma exacerbations [1]. However, this measurement is time consuming and requires specific technical expertise. Exhaled nitric oxide $(\mathrm{FeNO})$ is a noninvasive surrogate marker of eosinophilic airway inflammation that may be measured using small portable devices. Studies of using FeNO to titrate therapy have yielded mixed results $[2,3]$. However, it is possible that one-off clinic readings may not be the best method of utilising $\mathrm{FeNO}$, and the home monitoring potential of FeNO has not yet been fully explored.

We aimed i) to determine the reliability and feasibility of FeNO home monitoring in adults with moderate-to-severe asthma and ii) to investigate the relationship between serial FeNO measurements and recognised biomarkers of eosinophilic airways disease in asthma, specifically sputum and blood eosinophil counts. We hypothesised that serial FeNO measurements would correlate more closely with other biomarkers of eosinophilic airways disease than one-off readings, and that there may be a temporal relationship between FeNO and other eosinophil markers.

In this pilot study we recruited 10 adults (age $>18$ years) with moderate-to-severe asthma (Global Initiative for Asthma treatment steps 3-5 [4]), diagnosed by a specialist asthma physician in a secondary care setting, according to British Thoracic Society guidelines [5]. The study was approved by the National Research Ethics Committee - East Midlands Leicester, and all participants gave their written informed consent. The participant group comprised five men and five women with a mean \pm SD age of $64 \pm 5$ years. All participants were treated with inhaled corticosteroids $(800-2000 \mu \mathrm{g}$ per day beclometasone dipropionate equivalent) and long-acting $\beta_{2}$-agonists. Six patients received maintenance low-dose prednisolone (5-15 mg per day). Mean \pm SD post-bronchodilator forced expiratory volume in $1 \mathrm{~s}$ (FEV1) (\% pred) was $71.4 \pm 24.2$ with mean \pm SD bronchodilator reversibility of $9.3 \pm 11.2 \%$. A previous history of atopy was documented in three patients. Geometric mean ( $95 \%$ confidence interval) sputum eosinophil count was $6.1 \%(1.7-22.2 \%)$ and blood eosinophil count was $0.18 \times 10^{9}$ cells $\cdot \mathrm{L}^{-1}\left(0.07-0.46 \times 10^{9}\right.$ cells $\left.\cdot \mathrm{L}^{-1}\right)$.

Participants were recruited during the period from December 2013 - April 2014. They were each provided with a NObreath FeNO monitor (Bedfont Scientific, Maidstone, UK) and carefully instructed in its use. Participants were provided with a paper diary and asked to record three morning FeNO readings on a daily basis over a 56-day period. Participants attended study visits twice-weekly, at which time daily diaries were retrieved, a blood sample was drawn for measurement of eosinophil count, and sputum induction was performed (or a spontaneous sample obtained) [6]. Sputum cell counts were performed by an experienced technician.

Eight out of ten participants completed the study and good quality data were obtained in each case. The median missing data rate for home-monitored FeNO was 7.1\% (range 2.7-14.3\%). Home-monitored FeNO was repeatable, with a median intraclass correlation coefficient of triplicate measurements of 0.83 (range 0.78-0.92). Further analyses presented below utilise the average of the three daily FeNO measurements. Sputum samples were obtained and analysed successfully for 39 out of 40 study visits, with 36 of these being spontaneous samples.

In order to assess the relationship between $\mathrm{FeNO}$ and recognised biomarkers of eosinophilic airways disease, we constructed a linear mixed model (SPSS 20, IBM Corporation, Somers, New York, NY, USA) in which blood or sputum eosinophil count was the dependent variable and FeNO was specified as a fixed effect in the model. We specified an autoregressive covariance structure for the repeated measures of blood or sputum eosinophil count within each individual, since we observed that repeated measurements became less closely correlated with the passage of time. We performed our analysis using a range of lag periods and windows to determine 1) how changes in FeNO related temporally to changes in blood and sputum eosinophil counts, and 2) whether taking a moving average (window) of 3, 5, 7 or 9 consecutive days' FeNO readings could improve the correlation with blood and sputum eosinophil counts. Figure 1a-b show 

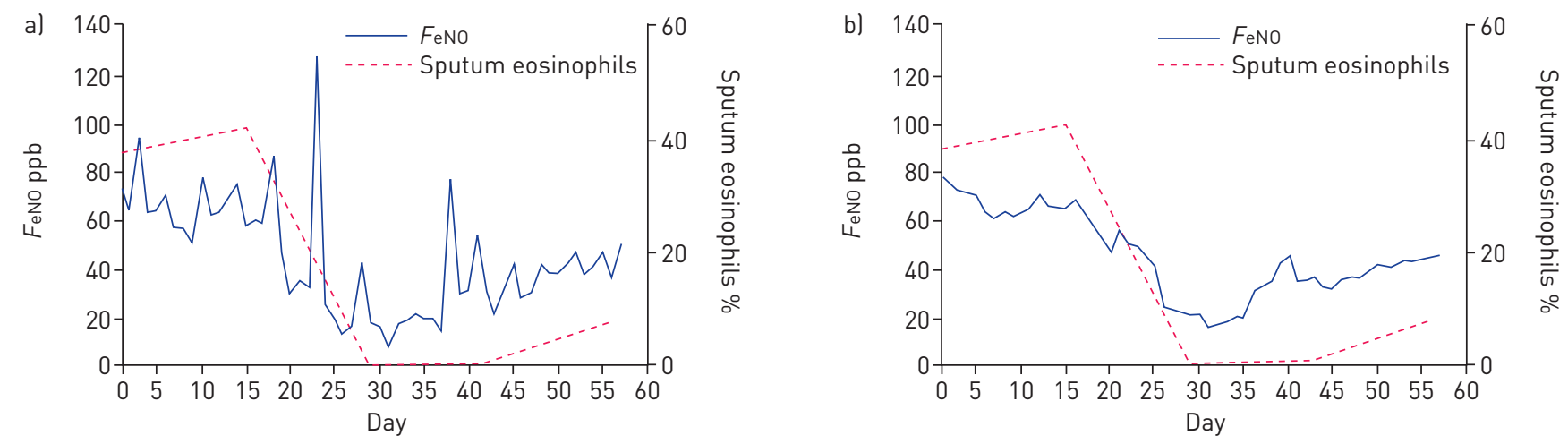

c)

\begin{tabular}{|c|c|c|c|c|c|}
\hline Lag & Window 1 & Window 3 & Window 5 & Window 7 & Window 9 \\
\hline-6 & 0.75 & 0.94 & 1.10 & 0.83 & 0.95 \\
\hline-5 & 0.90 & 0.92 & 1.00 & 1.36 & 1.15 \\
\hline-4 & 0.57 & 1.04 & 1.29 & 1.33 & 1.90 \\
\hline-3 & 1.09 & 1.30 & 1.48 & 1.89 & 1.81 \\
\hline-2 & 1.31 & 1.50 & 1.93 & 1.99 & 1.82 \\
\hline-1 & 1.07 & 1.82 & 2.03 & 1.82 & 1.85 \\
\hline 0 & 1.58 & 1.73 & 1.79 & 1.80 & 1.79 \\
\hline 1 & 1.04 & 1.56 & 1.60 & 1.73 & 1.79 \\
\hline 2 & 1.00 & 1.41 & 1.66 & 1.62 & 1.76 \\
\hline 3 & 1.47 & 1.44 & 1.54 & 1.69 & 1.61 \\
\hline 4 & 1.21 & 1.56 & 1.53 & 1.53 & 1.70 \\
\hline 5 & 0.91 & 1.30 & 1.53 & 1.50 & 1.59 \\
\hline 6 & 0.38 & 1.05 & 1.29 & 1.58 & 1.65 \\
\hline
\end{tabular}

d)

\begin{tabular}{|c|c|c|c|c|c|}
\hline Lag & Window 1 & Window 3 & Window 5 & Window 7 & Window 9 \\
\hline-6 & 0.77 & 0.61 & 1.14 & 1.05 & 1.10 \\
\hline-5 & 0.15 & 0.91 & 1.23 & 1.53 & 1.39 \\
\hline-4 & 0.62 & 1.08 & 1.39 & 1.38 & 1.34 \\
\hline-3 & 1.20 & 1.25 & 1.17 & 1.24 & 1.46 \\
\hline-2 & 0.67 & 0.98 & 1.11 & 1.37 & 1.32 \\
\hline-1 & 0.40 & 0.64 & 1.07 & 1.20 & 1.24 \\
\hline 0 & 0.19 & 0.50 & 0.80 & 1.05 & 1.02 \\
\hline 1 & 0.28 & 0.42 & 0.64 & 0.75 & 0.84 \\
\hline 2 & 0.39 & 0.65 & 0.49 & 0.50 & 0.61 \\
\hline 3 & 0.71 & 0.48 & 0.44 & 0.29 & 0.42 \\
\hline 4 & 0.10 & 0.37 & 0.29 & 0.31 & 0.28 \\
\hline 5 & 0.10 & -0.07 & 0.19 & 0.25 & 0.34 \\
\hline 6 & -0.56 & -0.09 & -0.02 & 0.20 & 0.23 \\
\hline
\end{tabular}

FIGURE 1 Relationship between domiciliary exhaled nitric oxide and eosinophilic inflammation. Overlaid time series of exhaled nitric oxide (Feno) and sputum eosinophil count in one participant, with a FeNO window of a) 1 day and b) 5 days. Colour maps indicating the effect size of Feno as a predictor of c) sputum eosinophil count and d) blood eosinophil count at a range of lag times and window sizes. A negative lag indicates that Feno

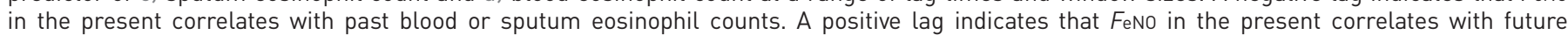
blood or sputum eosinophil counts.

example data from a single individual, demonstrating the relationship between $F$ eNO and sputum eosinophil count. Increasing the window width results in smoothing of the data, masking day-to-day variability in FeNO and allowing the underlying trends to be better seen.

Figure 1c-d demonstrates colour maps indicating the effect size of FeNO within the model to predict either sputum or blood eosinophil count at different lag periods and window sizes. A higher effect size indicates a stronger association. In these figures, a negative lag indicates that FeNO in the present correlates with past blood or sputum eosinophil counts. A positive lag indicates that FeNO in the present correlates with future blood or sputum eosinophil counts. The association between FeNO and sputum eosinophils was strongest at a lag of -1 and a window of 5, indicating that changes in sputum eosinophils tended to precede changes in FeNO by 1 day. The association between FeNO and blood eosinophils was strongest at a lag of -5 and a window of 7, indicating that changes in blood eosinophils tended to precede changes in FeNO by 5 days.

This is the first study to show that $F$ eNO is a reliable and repeatable method of measuring eosinophilic airway inflammation at home in patients with asthma. Our results indicate that maximal changes in FeNO appear to lag behind changes in sputum and blood eosinophils by 1 and 5 days respectively. However, FeNO can still give a good insight into the current level of sputum eosinophils, particularly if a moving average of 5-7 consecutive days' measurements is used. It should be noted that most patients in this study were able to provide spontaneous sputum samples and did not require formal induction with nebulised hypertonic saline. While spontaneous and induced sputum are not exactly equivalent, previous studies have indicated that the cellular content does not differ significantly between the two methods of expectoration [7].

The home monitoring approach has the advantage of patient convenience, as well as the potential for day-to-day adjustment of therapy or the detection and preventative treatment of incipient asthma exacerbations. НАSнімото et al. [8] recently performed a pragmatic randomised controlled trial in which an internet-based approach to oral corticosteroid tapering, incorporating domiciliary FeNO, was compared to a conventional approach. The internet algorithm was found to allow more rapid tapering of oral corticosteroids without any reduction in asthma control or quality of life. Honkoop et al. [9] found that adjustment of inhaled corticosteroid therapy in primary care using a symptom plus FeNO-driven strategy reduced asthma medication use while sustaining asthma control and quality of life. MALERBA et al. [10] 
found that titrating inhaled corticosteroids using a combination of FeNO and sputum eosinophils reduced exacerbation rates and asthma symptoms compared to a conventional strategy, without additional increases in inhaled corticosteroid doses.

In conclusion, serial FeNO measurements may identify airway inflammation within close temporal proximity to changes in conventional biomarkers of eosinophilic disease such as sputum eosinophil count, with the added value of being of point-of-care. Further prospective trials are required to assess if this approach can successfully predict exacerbations or be used to titrate therapy in adults with asthma.

0 @ERSpublications

Exhaled nitric oxide home monitoring is a promising surrogate marker of eosinophilic airway inflammation in asthma http://ow.ly/108ak4

Catriona Ruth $\operatorname{Nanda}^{1}$, Amisha Singapuri ${ }^{1}$, Marcia Soares ${ }^{1}$, William Monteiro ${ }^{1}$, Salman Siddiqui ${ }^{1,2}$ and Sherif Gonem ${ }^{1,2}$ ${ }^{1}$ Institute for Lung Health, Department of Infection, Immunity and Inflammation, University of Leicester, UK.

${ }^{2}$ Both authors contributed equally.

Correspondence: Sherif Gonem, Leicester Respiratory BRU, Glenfield Hospital, Groby Road, Leicester, LE3 9QP, UK. E-mail: sg330@le.ac.uk

Received: Dec 082015 | Accepted after revision: March 042016 | First published online: April 212016

Support statement: This paper presents independent research funded by the National Institute for Health Research (NIHR). The views expressed are those of the authors and not necessarily those of the NHS, the NIHR or the Department of Health. We gratefully acknowledge the loan of NObreath devices from Bedfont Scientific Ltd. Funding information for this article has been deposited with FundRef.

Conflict of interest: Disclosures can be found alongside this article at erj.ersjournals.com

\section{References}

1 Green RH, Brightling CE, McKenna S, et al. Asthma exacerbations and sputum eosinophil counts: a randomised controlled trial. Lancet 2002; 360: 1715-1721.

2 Petsky HL, Cates CJ, Lasserson TJ, et al. A systematic review and meta-analysis: tailoring asthma treatment on eosinophilic markers (exhaled nitric oxide or sputum eosinophils). Thorax 2012; 67: 199-208.

3 Powell $\mathrm{H}$, Murphy VE, Taylor DR, et al. Management of asthma in pregnancy guided by measurement of fraction of exhaled nitric oxide: a double-blind, randomised controlled trial. Lancet 2011; 378: 983-990.

4 Global Strategy for Asthma Management and Prevention. Global Initiative for Asthma (GINA) 2010. www.ginasthma.org/ Date last updated: May 6, 2015. Date last accessed: December 8, 2015.

5 British Guideline on the Management of Asthma. British Thoracic Society/Scottish Intercollegiate Guidelines Network 2008. www.brit-thoracic.org.uk/guidelines/asthma-guidelines.aspx Date last updated: October 1, 2014. Date last accessed: December 8, 2015.

6 Pavord ID, Pizzichini MM, Pizzichini E, et al. The use of induced sputum to investigate airway inflammation. Thorax 1997; 52: 498-501.

7 Pizzichini MM, Popov TA, Efthimiadis A, et al. Spontaneous and induced sputum to measure indices of airway inflammation in asthma. Am J Respir Crit Care Med 1996; 154: 866-869.

8 Hashimoto S, Brinke AT, Roldaan AC, et al. Internet-based tapering of oral corticosteroids in severe asthma: a pragmatic randomised controlled trial. Thorax 2011; 66: 514-520.

9 Honkoop PJ, Loijmans RJ, Termeer EH, et al. Symptom- and fraction of exhaled nitric oxide-driven strategies for asthma control: A cluster-randomized trial in primary care. J Allergy Clin Immunol 2015; 135: 682-688.

10 Malerba M, Radaeli A, Olivini A, et al. The combined impact of exhaled nitric oxide and sputum eosinophils monitoring in asthma treatment: a prospective cohort study. Curr Pharm Des 2015; 21: 4752-4762.

\section{Quality standards for the management of bronchiectasis in Italy: a national audit}

\section{To the Editor:}

Although historically considered a neglected disease, bronchiectasis has become a disease of renewed interest over recent decades in light of an increase in prevalence and a substantial burden on healthcare systems [1-3]. In 2010, the British Thoracic Society (BTS) published guidelines on the management of bronchiectasis in adults, along with specific quality standards $[4,5]$. To date, these represent the only 